\title{
SIMULTANEOUS DUAL-WAVELENGTH GENERATION FROM VERTICAL EXTERNAL-CAVITY SURFACE-EMITTING SEMICONDUCTOR LASERS
}

\author{
S. Ranta ${ }^{\text {a }}$, T. Leinonen ${ }^{\text {a }}$, A. Härkönen ${ }^{\text {a }}$, A. Laakso ${ }^{\text {a }}$, Y. Morozov $^{b}$, and M. Pessa ${ }^{\text {a }}$ \\ ${ }^{a}$ Optoelectronics Research Centre, Tampere University of Technology, P.O. Box 692, FI-33101 Tampere, Finland \\ E-mail: sanna.ranta@tut.fi \\ ${ }^{\mathrm{b}}$ Institute of Radio Engineering and Electronics (Saratov Branch), Russian Academy of Sciences, Zelenaya 38, 410019 \\ Saratov, Russia
}

Received 26 August 2009; revised 15 October 2010; accepted 19 March 2010

\begin{abstract}
We demonstrate dual-wavelength emission from optically pumped vertical-external-cavity surface-emitting lasers (VECSELs) with two different gain mirror designs. The first gain mirror design $(S 1)$ generated an optical output power of $0.39 \mathrm{~W}$ at $\lambda_{\mathrm{S}}=984 \mathrm{~nm}$ and $0.30 \mathrm{~W}$ at $\lambda_{\mathrm{L}}=1042 \mathrm{~nm}$. A VECSEL using the second gain mirror design (S2) generated a maximum optical output power of $0.75 \mathrm{~W}$ at $\lambda_{\mathrm{S}}=966 \mathrm{~nm}$ and $1.38 \mathrm{~W}$ at $\lambda_{\mathrm{L}}=1047 \mathrm{~nm}$. VESCELs using either gain mirror design exhibited self-pulsating behaviour in the high output power regime. In the VECSEL using the $S 1$ gain mirror design, self-pulsation started beyond the $\lambda_{\mathrm{S}}$ output power of $140 \mathrm{~mW}$ and $\lambda_{\mathrm{L}}$ output power of $115 \mathrm{~mW}$. The corresponding output power limits in the VECSEL using the $S 2$ gain mirror were $300 \mathrm{~mW}$ for both wavelengths.
\end{abstract}

Keywords: vertical external-cavity surface-emitting lasers, resonant periodic gain structure, semiconductor lasers

PACS: $42.55 . P x, 42.60 . B y$

\section{Introduction}

Two-wavelength lasers are particularly interesting light sources with applications ranging from nonlinear frequency mixing [1] to two-wavelength interferometry [2]. An ideal light source for these applications would emit two diffraction-limited, high power co-axial beams with sufficiently large wavelength separation. Due to their compact size, large gain bandwidth, and possibility for wavelength tailoring, semiconductor lasers are particularly well suited for two-wavelength applications.

A vertical coupled-cavity surface-emitting laser is capable of meeting these requirements [3]. Furthermore, such laser geometry offers good beam quality in a compact form. Coupled-cavity structures, however, can only achieve relatively small wavelength separation, typically less than $30 \mathrm{~nm}$ in the near infrared, with fairly small output powers in the order of milliwatts [3]. This separation is not enough for some applications. For example, the wavelength separation is not large enough to reach difference frequencies in the mid-infrared region. Another device capable of dualwavelength emission is a wide-band-gain semiconduc- tor optical amplifier (SOA) using an external grating to couple two different gain stripes, located on a single chip, into a single cavity [4]. With this approach, dual-wavelength emission with a wavelength separation of more than $170 \mathrm{~nm}$ in the near infrared can be achieved [5]. An arbitrarily large wavelength separation can be achieved from a similar device, a gratingcoupled edge-emitting laser, which comprises two or more chips emitting light at different wavelengths and an external grating that combines the two beams into one co-axial beam. These approaches have disadvantages in terms of the complex optics required for coupling the elliptical beams emitted by the gain stripes.

To combine the advantageous features of vertical coupled-cavity devices and those offered by broadband SOAs we have developed optically pumped verticalexternal-cavity surface-emitting lasers (VECSELs [6, 7]) with emission at two wavelengths which are well separated. Figure 1 shows typical VECSEL elements. The laser cavity is formed between the gain mirror and an external mirror, which also acts as an output coupler. The gain mirror has a resonant periodic gain (RPG) structure comprising quantum wells (QWs) for gain and a distributed Bragg reflector [8]. The pump light is ab- 


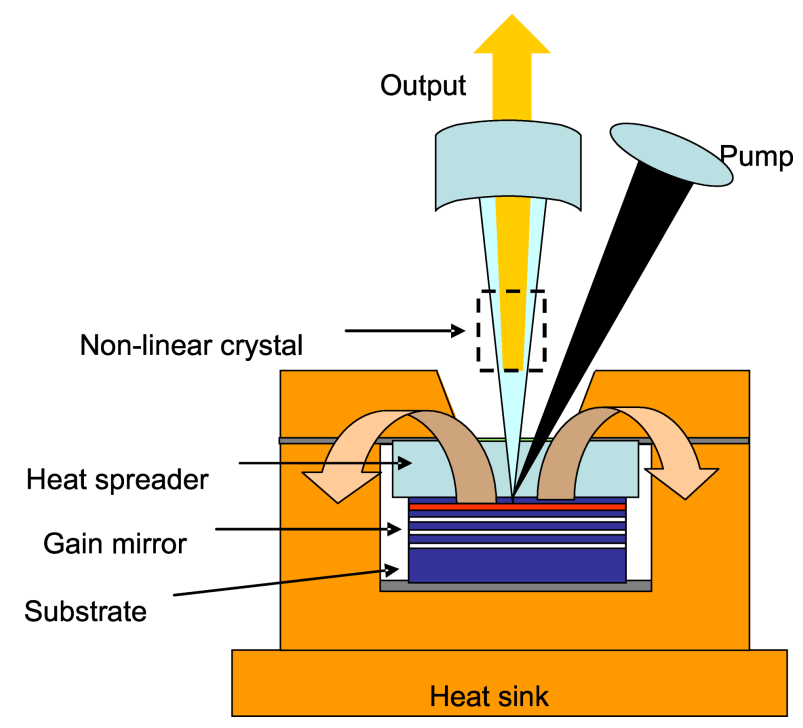

Fig. 1. Schematic of a typical VECSEL set-up.

sorbed by the quantum well barriers and the carriers are captured by the QWs. Efficient heat conduction away from the gain mirror is crucial for high-power operation. Typically, diamond [9] is used as a heat spreader which is located either inside the laser cavity (as in the figure) [10] or outside the laser cavity (see, for example, [7]).

The VECSELs are designed to emit the two light beams co-axially sharing a single external cavity, which makes these devices compact. The vertical externalcavity geometry offers scalability to watt-level optical output power in a circular TEM 00 mode. Furthermore, VECSEL development requires relatively simple processes, and the external cavity enables intracavity optical components, such as nonlinear optical crystals, semiconductor saturable absorbers, and wavelength selective filters to be incorporated. The possibility to exploit intra-cavity frequency conversion and wavelength filtering is particularly important because it enables efficient nonlinear conversion and high-power single-frequency operation [11].

\section{Design of the gain structures}

There are two major obstacles involved in the design of a gain mirror for a semiconductor based dualwavelength VECSEL. The first, and the more difficult to deal with, is the absorption of the short wavelength signal, $\lambda_{\mathbf{S}}$, in the long wavelength, $\lambda_{\mathrm{L}}$, quantum-well gain medium. The absorption is caused by the states above the lasing wavelength. The second problem is the equalization of the beam intensities. The need for equalization arises from non-uniform pumping of the

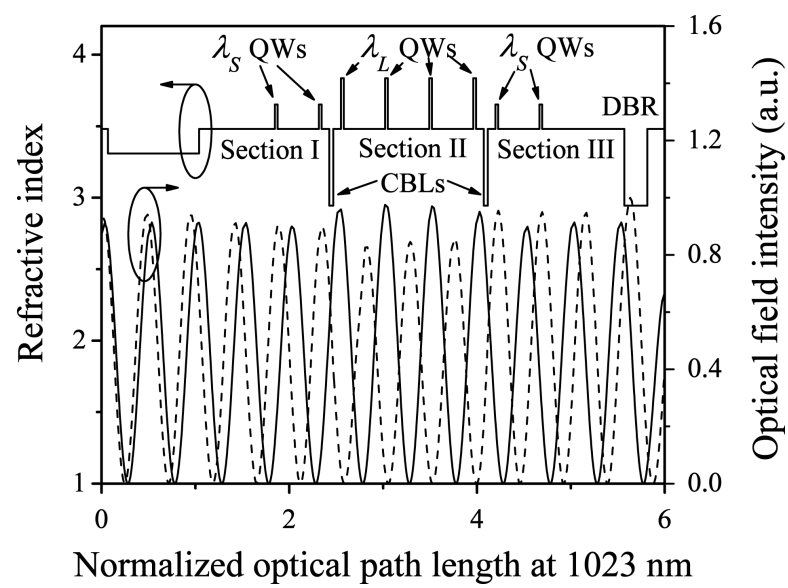

Fig. 2. Refractive index profile of $S 1$ in resonant periodic gain region and optical field intensities at $\lambda_{\mathrm{S}}$ (dashed line) and $\lambda_{\mathrm{L}}$ (solid line). Diamond/semiconductor interface is located at 0 optical path length. Pump light enters $S 1$ from the left side of this interface.

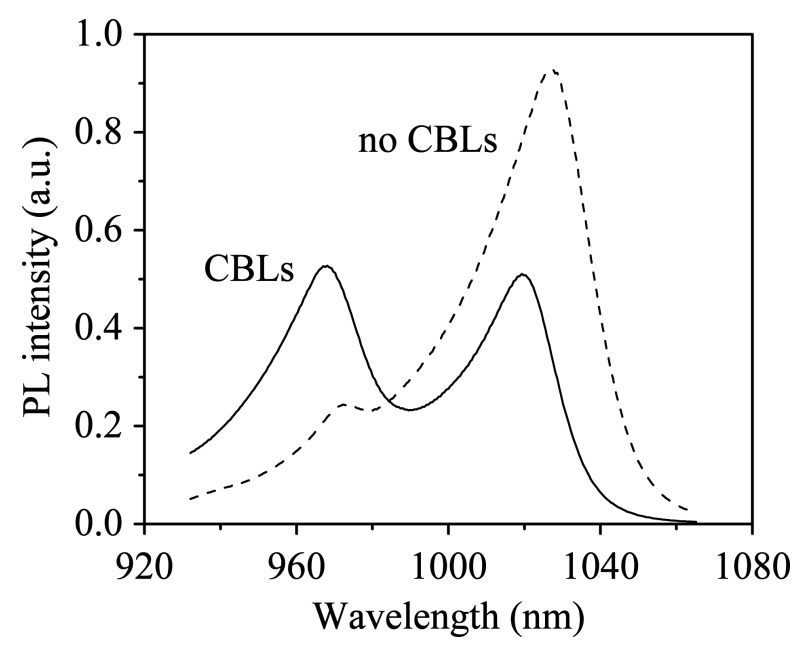

Fig. 3. Spectra of samples with (solid line) and without (dashed line) carrier blocking layers (CBLs).

quantum wells inside a VECSEL structure - the pump light is absorbed as it traverses the gain mirror, being about $20 \%$ of the initial value close to the bottom of the resonant period gain structure used in VECSELs.

The gain mirrors we have designed for emissions at two wavelengths $\left(\lambda_{\mathrm{S}} \& \lambda_{\mathrm{L}}\right)$ are based on QWs. The first structure $(S 1)$ had QWs inside a single RPG structure [12]. The single RPG, however, was divided into three sections by carrier blocking layers (CBLs, Fig. 2). The first and third sections contained two $\lambda_{\mathrm{S}}$ QWs each and the second four $\lambda_{\mathrm{L}}$ QWs. The blocking layers eliminated carrier flow between the three sections, allowing different carrier populations for each section. Had the sections, and thus the QWs, shared the same carrier population, the $\lambda_{\mathrm{S}}$ QWs would not have been inverted at all. This is because most of the pump-generated carriers would have been captured by the deeper $\lambda_{\mathrm{L}}$ QWs 


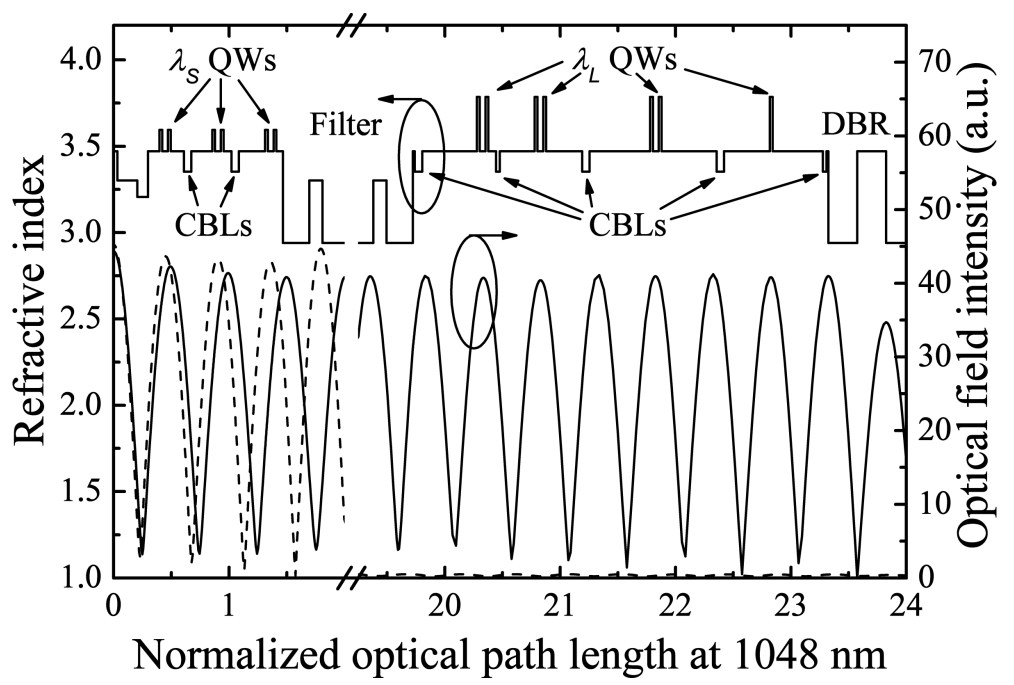

Fig. 4. Refractive index profile of $S 2$ in both resonant periodic gain regions and optical field intensities at $\lambda_{\mathrm{S}}$ (dashed line) and $\lambda_{\mathrm{L}}$ (solid line). Optical pumping is introduced and laser emission occurs at the same directions as in $S 1$ (see Fig. 1).

at the expense of the shallower $\lambda_{\mathrm{S}} \mathrm{QWs}$, leading to an unequal pumping of the different QW types. This pumping inequality was tested with two samples, one of which had one $\lambda_{\mathrm{L}}$ and one $\lambda_{\mathrm{S}}$ QWs in the same section, whereas the other had a carrier blocking layer between the QWs (see Fig. 3). The sample without the CBLs showed much worse photoluminescence performance at the shorter wavelength, as seen in Fig. 3. Furthermore, the inequality of the pump beam intensity had to be taken into account in the VECSEL design. The beam intensity drops as it is absorbed by the RPG structure. This leads to highest pumping of the QWs near the surface. This phenomenon is enhanced by the CBLs as compared to the conventional VECSEL mirrors without such blocking layers. The pumping inequality caused by the pump beam intensity decrease was compensated for by having two of the $\lambda_{\mathrm{S}}$ QWs in the high intensity pumping regime (section $I$ in Fig. 2) and two in the low intensity pumping regime (section III), whereas all four $\lambda_{\mathrm{L}} \mathrm{QWs}$ were located in the intermediate intensity pumping regime (section $I I$ ).

A highly reflective distributed Bragg reflector (DBR) made of AlAs/GaAs was situated beneath the RPG to provide the mirror feedback for the laser cavity. The index contrast of such a mirror is just sufficient to realize a stop band wide enough for both wavelengths. The material dispersion of the gain mirror alone would not have been enough to separate the two wavelengths far enough to have $\lambda_{\mathrm{L}}$ anti-nodes and $\lambda_{\mathrm{S}}$ nodes coincide in the RPG structure at the $\lambda_{\mathrm{L}} \mathrm{QW}$ locations. The required separation was provided by the different phaseshifts experienced by the two wavelengths near the opposite edges of the DBR.
The second gain mirror structure $(S 2)$ was developed to reduce the stringent growth precision required by $S 1$, in which a small misalignment of the $\lambda_{\mathbf{S}}$ standing optical wave in respect to the $\lambda_{\mathrm{L}} \mathrm{QWs}$ (about $6 \mathrm{~nm}$ ) is enough to cause significant absorption of $\lambda_{\mathrm{S}}$ [13]. Furthermore, the design allowed a more straightforward implementation of larger wavelength separations than $S 1$. A large wavelength separation is also possible with a single-RPG structure similar to $S 1$, but the DBR has to be replaced with one having multiple stop bands.

The $S 2$ had two separate RPG structures, one for each wavelength [14]. The RPG containing the $\lambda_{S}$ QWs was closer to the gain mirror surface (see Fig. 4). The QWs were organized in sections, each containing a single QW pair, except for the last $\lambda_{\mathrm{L}} \mathrm{QW}$. All sections were separated by either CBLs or a long-wave pass filter. Since the pump beam intensity had dropped significantly from the initial value (to about $23 \%$ ) at the last section, the section had only one QW. The pumping of the sections was equalized by having each section absorb similar amounts of the pump light. This was done by tuning the barrier layer thicknesses of each section. The amount of pump light absorbed was deduced by simulating the field intensity within the gain mirror structure, taking into account the absorption in the QW and barrier layers.

The $\lambda_{\mathrm{L}}$ QWs were made of $7-\mathrm{nm} \mathrm{Ga} \mathrm{Ga}_{0.75} \mathrm{In}_{0.25} \mathrm{As}$ layers and the $\lambda_{\mathrm{S}}$ QWs were made of 7-nm $\mathrm{Ga}_{0.86} \mathrm{In}_{0.14}$ As layers, resulting in lattice strains of -1.79 and $-1.00 \%$, respectively. The CBL material was $\mathrm{GaAs}_{0.70} \mathrm{P}_{0.30}$, whose tensile lattice strain (1.08\%) 


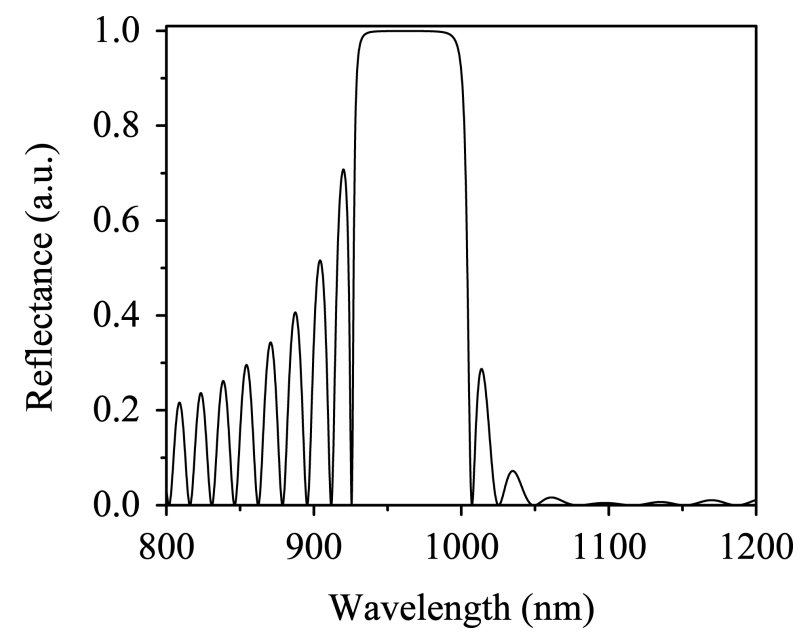

Fig. 5. Reflectance spectrum of the long-wave pass filter. The filter is designed to reflect $\lambda_{\mathrm{S}}$ and transmit $\lambda_{\mathrm{L}}$. Therefore, $\lambda_{\mathrm{S}}$ is located in the stop band of the filter and $\lambda_{\mathrm{L}}$ in the minimum reflectance region.

was designed to compensate fully the lattice strain induced by the QWs according to

$$
\varepsilon_{\mathrm{QW}, \lambda_{i}} N_{\mathrm{QW}, \lambda_{i}} d_{\mathrm{QW}, \lambda_{i}}=\varepsilon_{\mathrm{CBL}, \lambda_{i}} N_{\mathrm{CBL}, \lambda_{i}} d_{\mathrm{CBL}, \lambda_{i}} .
$$

In Eq. (1) $N_{\mathrm{QW}, \lambda_{i}}$ and $N_{\mathrm{CBL}, \lambda_{i}}$ are the total number of $\lambda_{i}$ QWs and CBLs that are located in $\lambda_{i}$ RPG, $d_{\mathrm{QW}, \lambda_{i}}$ and $d_{\mathrm{CBL}, \lambda_{i}}$ are their thicknesses, and $\varepsilon_{\mathrm{QW}, \lambda_{i}}$ and $\varepsilon_{\mathrm{CBL}, \lambda_{i}}$ are their lattice strains.

The RPGs in $S 2$ were separated by a long-wave pass filter, which was designed to have a transmission maximum for $\lambda_{\mathrm{L}}$ and a reflectance maximum for $\lambda_{\mathrm{S}}$, thus keeping $\lambda_{\mathrm{S}}$ from entering the $\lambda_{\mathrm{L}} \mathrm{QWs}$ and preventing absorption. The filter had a low amount of undulating reflection on the pass-side, which diminished as the wavelength increased (see Fig. 5). Since $\lambda_{\mathrm{L}}$ was relatively close to the cut-off wavelength of the filter, the filter still had a small amount of reflectivity close to $\lambda_{\mathrm{L}}$ and was fitted in such a way that $\lambda_{\mathrm{L}}$ coincided with a minimum of the undulating reflection (see Fig. 5). The filter had 39 periods of $\mathrm{Al}_{0.30} \mathrm{Ga}_{0.7} \mathrm{As} / \mathrm{AlAs} / \mathrm{Al}_{0.30} \mathrm{Ga}_{0.7} \mathrm{As}$, surrounded by AlAs phase-matching layers to reduce the ripple amplitude on the pass-band side. The thickness of the AlAs layers was $81.41 \mathrm{~nm}$ and the thickness of the $\mathrm{Al}_{0.30} \mathrm{Ga}_{0.7} \mathrm{As}$ layers was about $36 \mathrm{~nm}$. The mirror feedback for the $\lambda_{\mathrm{S}}$ was provided by the filter, and the feedback for the $\lambda_{\mathrm{L}}$ by a DBR beneath the $\lambda_{\mathrm{L}} \mathrm{RPG}$ structure. Due to the thick filter (about $6 \mu \mathrm{m}$ ), $S 2$ had a significantly higher thermal impedance for $\lambda_{\mathrm{L}}$ as compared to $S 1$.

Both structures were terminated by a thin GaAs capping layer (thickness $d=20 \mathrm{~nm}$ in $S 1$ and $d=10 \mathrm{~nm}$ in $S 2$ ), whose purpose was to protect the $\mathrm{Al}_{0.30} \mathrm{Ga}_{0.7} \mathrm{As}$
Table 1. Semiconductor layer structure of the PL sample.

\begin{tabular}{ccc}
\hline Layer & Material & Thickness $(\mathrm{nm})$ \\
\hline Cap & $\mathrm{GaAs}$ & 25 \\
Carrier confinement & $\mathrm{AlAs}$ & 100 \\
Barrier & $\mathrm{GaAs}$ & 100 \\
$\lambda_{\mathrm{S}} \mathrm{QW}$ & $\mathrm{Ga}_{0.86} \mathrm{In}_{0.14} \mathrm{As}$ & 7 \\
Barrier & $\mathrm{GaAs}$ & 25 \\
CBL & $\mathrm{AlAs}$ & 15 \\
Barrier & $\mathrm{GaAs}$ & 25 \\
$\lambda_{\mathrm{L}} \mathrm{QW}$ & $\mathrm{Ga}_{0.75} \mathrm{In}_{0.25} \mathrm{As}$ & 7 \\
Barrier & $\mathrm{GaAs}$ & 100 \\
Carrier confinement & $\mathrm{AlAs}$ & 300 \\
Buffer & $\mathrm{GaAs}$ & 200 \\
Substrate & $n$-GaAs & \\
\hline
\end{tabular}

layer during the processing steps involved in the chip mounting. Beneath the capping layer both structures had a window layer $(d=300 \mathrm{~nm}$ in $S 1$ and $d=55 \mathrm{~nm}$ in $S 2$ ) to prevent carriers leaking to the gain mirror surface. The thicknesses of the capping and the window layers were made as thin as possible in order to minimize the thermal impedance between the gain regions and the gain mirror surface. The structures were resonant for both $\lambda_{\mathrm{S}}$ and $\lambda_{\mathrm{L}}$. In $S 1$, the window layer had to be thicker than in $S 2$ in order for both $\lambda_{\mathrm{S}}$ and $\lambda_{\mathrm{L}}$ to be resonant at the same time. In $S 2$, the $\lambda_{\mathrm{S}}$ resonance was first matched with the window layer, and the $\lambda_{\mathrm{L}}$ resonance was then matched with the thicknesses of the $\lambda_{\mathrm{L}}$ gain section barrier layers. In both designs, $\lambda_{\mathrm{L}} \mathrm{QWs}$ and $\lambda_{\mathrm{S}}$ QWs are located near the antinodes of the optical standing field of the corresponding wavelength in order to maximize the gain for each wavelength.

\section{Gain mirror fabrication and characterization set-ups}

Both $S 1$ and $S 2$ were grown and attached to gainmirror carriers in similar fashions. The gain mirrors were fabricated in a single solid-source molecularbeam-epitaxy growth step on a $2^{\prime \prime} n$-GaAs substrate. For the laser to operate at the desired wavelength, the room-temperature QW emission wavelength was calibrated before the gain mirror growth by using a photoluminescence (PL) sample containing QWs for both wavelengths, CBL between the QWs, and carrier confining AlAs-layers (see Table 1). A thin GaAs layer was grown on top of the photoluminescence sample in order to prevent the AlAs layers from oxidation. To accommodate the wavelength shift induced by heating of the gain mirrors during laser operation, the room temperature emission targets were set about $15 \mathrm{~nm}$ shorter than the desired lasing wavelengths. The emission wave- 


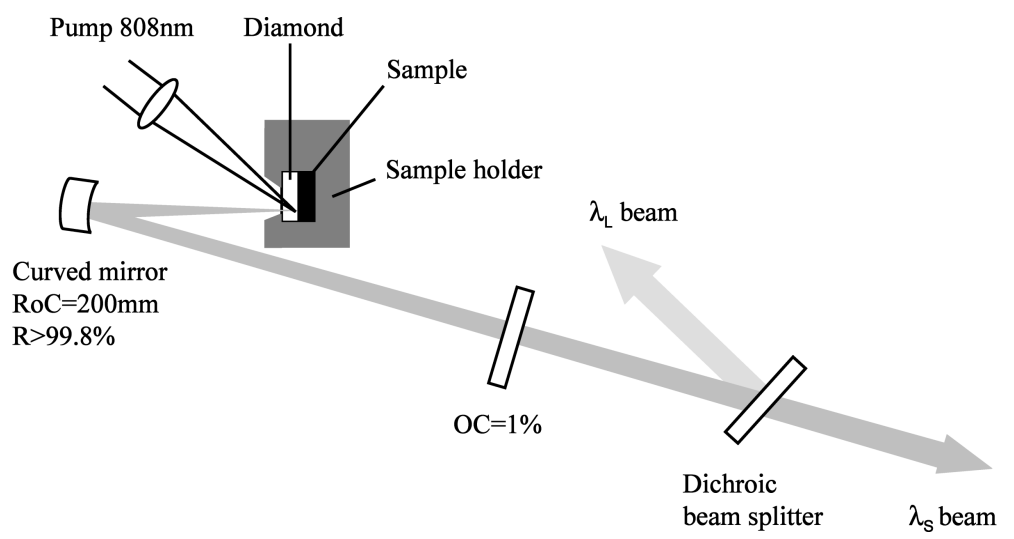

Fig. 6. VECSEL configuration. The distance between the curved mirror and the gain chip is $130 \mathrm{~mm}$ for $S 1$ and $135 \mathrm{~mm}$ for $S 2$. The planar output coupler (OC) is located 385 and $241 \mathrm{~mm}$ away from the curved mirror in the case of $S 1$ and $S 2$, respectively.

length was tuned by changing the QW compositions according to measurement data obtained from the PL sample. Since accurate layer thicknesses are crucial for proper device operation, the growth rates of aluminium and gallium cells were calibrated carefully before each gain mirror growth.

High arsenic beam flux, as determined by the chamber background pressure, was employed during the epitaxial growth ( $p \sim 1.3-1.4 \cdot 10^{-6}$ mbar), since this seemed to yield better crystalline quality as compared to the pressure typically used, for example, during the growth of edge-emitting lasers $(p \sim 3-$ $4 \cdot 10^{-7}$ mbar). For surface emitting lasers, a pressure of $p \sim 6 \cdot 10^{-7}$ mbar would usually yield a rough wafer surface, as determined by examining the surface with a phase-contrast microscope. The surface roughness problem was particularly severe for $S 2$. This problem is most likely linked to the GaAs/AlAs interfaces present in the DBR and filter layers. $S 2$ contains more of these interfaces ( $S 1$ : 62 interfaces, $S 2: 143$ interfaces). During the DBR and filter structure growth in $S 2$, the growth was interrupted for 5 seconds at each DBR or filter interface. It was believed that this approach would help smooth wafer surfaces to be achieved. This technique, however, did not result in a noticeable improvement.

After the epitaxial growth, the wafers were diced into chips of about $2 \times 2 \mathrm{~mm}^{2}$ in size. The chips were capillary bonded [15] on a 300- $\mu$ m thick transparent type IIa diamond window which functioned as an intra cavity heat spreader. The diamond window was attached to a copper sample holder by mechanical pressure and with the aid of thin $(50 \mu \mathrm{m})$ indium foil. The heat generated at the gain mirror would exit through the diamond heat spreader and the indium foil to the copper mount. After the chip bonding, a two-layer anti-reflective dielectric coating was applied to the diamond surface by electron beam evaporation.

The performances of the gain mirrors were characterized in a V-shaped VECSEL cavity (Fig. 6). The gain chips were optically pumped with 808-nm fibrecoupled diode lasers at a copper mount temperature of $15^{\circ} \mathrm{C}$. The calculated pump spot diameters on the gain mirror surfaces, not taking into account the pump angle, were 124 and $180 \mu \mathrm{m}$ for $S 1$ and $S 2$, respectively. Therefore, the pump spot area used in $S 2$ characterization was about twice the area used in $S 1$ characterization. The pump beam was set at a $40^{\circ}$ angle for $S 1$ and at a $35^{\circ}$ angle for $S 2$. The $S 1$ mount was cooled by a water cooling circuit and $S 2$ was cooled by a thermoelectric cooler, which in turn was water cooled. For independent characterization the output wavelengths were separated with the aid of a dichroic beam splitter. The temporal behaviours of the separated beams were studied by measuring the intensities with a 1-GHz silicon detector. The output powers of the beams were measured with two calibrated thermopile sensors. The output spectra of the lasers were studied without the dichroic filter.

\section{Results and discussions}

The laser using the $S 1$ gain mirror emitted light at wavelengths of $\lambda_{\mathrm{S}, S 1}=982 \mathrm{~nm}$ and $\lambda_{\mathrm{L}, S 1}=1042 \mathrm{~nm}$ (see Fig. 7), while the laser based on $S 2$ mirror emitted light at $\lambda_{\mathrm{S}, S 2}=966 \mathrm{~nm}$ and $\lambda_{\mathrm{L}, S 2}=1047 \mathrm{~nm}$ (see Fig. 8). Consequently, the wavelength separation, $\Delta \lambda$, was $60 \mathrm{~nm}$ for $S 1$ and $81 \mathrm{~nm}$ for $S 2$.

$S 1$ generated maximum continuous-wave (cw) optical power of $0.14 \mathrm{~W}$ at $\lambda_{\mathrm{S}, S 1}$ and $0.115 \mathrm{~W}$ at $\lambda_{\mathrm{L}, S 1}$ (Fig. 9) with maximum slope efficiencies of 10 and $8 \%$, respectively. The lasing thresholds were reached at 


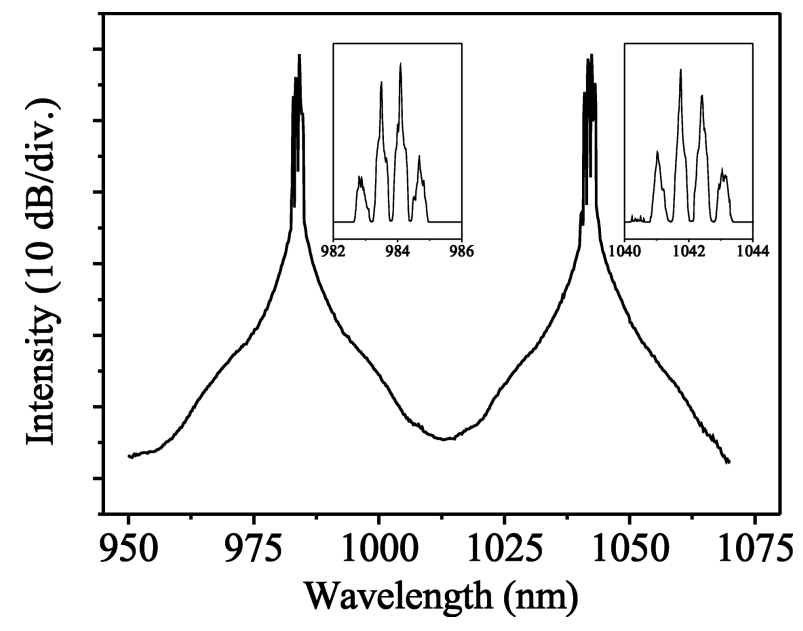

Fig. 7. Output spectrum of the VECSEL using $S 1$ gain mirror. The insets show spectra on a magnified scale close to the emission peaks.

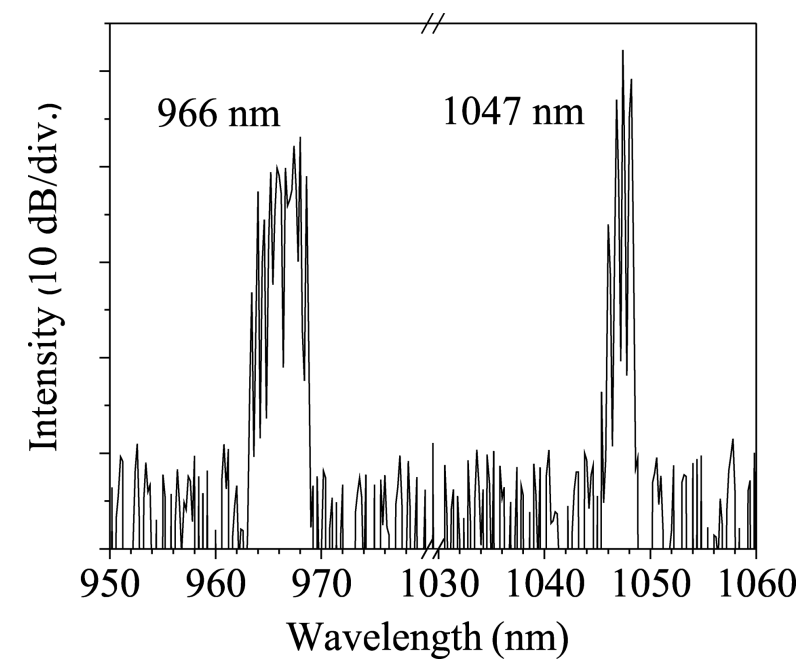

Fig. 8. Output spectrum of the VECSEL using the gain mirror $S 2$.

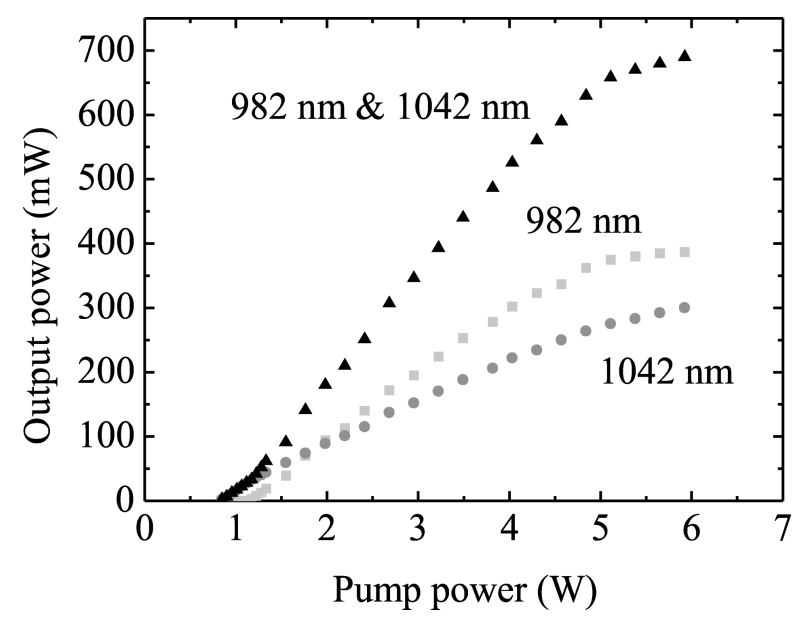

Fig. 9. Light output graph of the VECSEL using $S 1$ gain mirror.

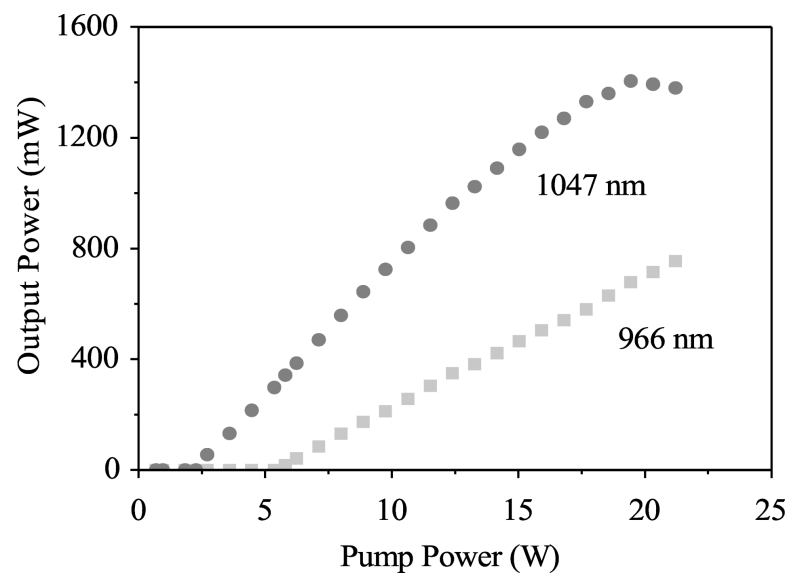

Fig. 10. Light output graph of the VECSEL using $S 2$ gain mirror.

pump powers of $1.15 \mathrm{~W}$ for $\lambda_{\mathrm{S}, S 1}$ and $0.85 \mathrm{~W}$ for $\lambda_{\mathrm{L}, S 1}$. The laser output remained $\mathrm{cW}$ up to a pump power of $2.4 \mathrm{~W}$. Beyond this pump power, both wavelengths showed strong in-phase self pulsation. The maximum combined output power of both wavelengths in this selfpulsating mode was about $700 \mathrm{~mW}$ at a pump power of $6 \mathrm{~W}$, corresponding to a $\lambda_{\mathrm{S}, S 1}$ output power of about $390 \mathrm{~mW}$ and a $\lambda_{\mathrm{L}, S 1}$ power of about $300 \mathrm{~mW}$. In both $x$ and $y$ directions, the beam propagation factor was $M^{2}=1.04$, which indicates excellent beam quality.

The laser using the $S 2$ gain mirror generated maximum cw optical power of $0.75 \mathrm{~W}$ at $\lambda_{\mathrm{S}, S 2}$ at the pump power of $21.2 \mathrm{~W}$ and $1.4 \mathrm{~W}$ at $\lambda_{\mathrm{L}, S 2}$ at the pump power of $19.4 \mathrm{~W}$ (Fig. 10). The lasing thresholds were reached at the pump powers of 5.4 and $2.3 \mathrm{~W}$ for $\lambda_{\mathrm{S}, S 2}$ and $\lambda_{\mathrm{L}, S 2}$, respectively. $M^{2}$ was 1.38 in the $x$ direction and 1.51 in the $y$ direction. Like the VECSEL using the gain mirror $S 1$, both wavelengths showed self-pulsating behaviour at output powers exceeding $300 \mathrm{~mW}$. The maximum output powers in the self-pulsating mode was about $750 \mathrm{~mW}$ for $\lambda_{\mathrm{S}, S 2}$ and $1400 \mathrm{~mW}$ for $\lambda_{\mathrm{L}, S 2}$. The combined output power reached its maximum of about $2100 \mathrm{~mW}$ at a pump power of $21 \mathrm{~W}$. The maximum slope efficiencies for $\lambda_{\mathrm{S}, S 2}$ and $\lambda_{\mathrm{L}, S 2}$ were approximately 5 and $10 \%$, respectively.

The VECSEL using the $S 2$ gain mirror generated a higher maximum optical output power at each wavelength as compared to the VECSEL using the $S 1$ gain mirror. This difference is not entirely explained by the difference in the pump spot size alone, which was about twice as large for the VECSEL using the gain mirror design $S 2$ than the VECSEL using the gain mirror design $S 1$. Therefore, it seems that $S 2$ is a more suitable design for high-power operation. This may be due to the larger number of QWs for both wavelengths in $S 2$. The wavelength separation is greater for the VECSEL using the $S 2$ gain mirror than for the VECSEL using the 
$S 1$ gain mirror. This is because the separated feedback of $\lambda_{\mathrm{L}}$ and $\lambda_{\mathrm{S}}$ allows the $\Delta \lambda$ to exceed the AlAs/GaAs DBR stop-band width.

The gain equalization was more successful in $S 1$ than in $S 2$. In $S 2, \lambda_{\mathrm{L}}$ exhibited lower threshold and higher slope efficiency than $\lambda_{\mathrm{S}}$, despite the higher thermal impedance between the $\lambda_{\mathrm{L}}$ gain region and the diamond heat spreader. The higher thermal impedance, however, may be the reason why $\lambda_{\mathrm{L}}$ exhibits thermal roll-over at lower pump powers than $\lambda_{S}$. The higher slope efficiency of $\lambda_{\mathrm{L}}$ in the VECSEL using the $S 1$ gain mirror can be attributed to the depth of the $\lambda_{\mathrm{L}} \mathrm{QWs}$, which, being deeper than the $\lambda_{\mathrm{S}} \mathrm{QWs}$, have higher carrier capture efficiency [12]. The capture efficiency may also be the cause of the thermal roll-over behaviour observed in the same VECSEL - in this VECSEL, where the thermal impedance of both wavelength's gain regions are similar, $\lambda_{\mathrm{S}}$ rolls over at a lower pump intensity than $\lambda_{\mathrm{L}}$.

To improve the designs, the gain equalization of $S 2$ can be enhanced by reducing the number of $\lambda_{\mathrm{L}} \mathrm{QWs}$ and its RPG structure thickness. At the same time, the number of $\lambda_{\mathrm{S}} \mathrm{QWs}$, together with the $\lambda_{\mathrm{S}}$ RPG structure thickness, should be increased in order to use the pump light effectively. The wavelength separation achieved with $S 1$ can be increased by the use of multi-stop-band DBRs [16]. To suppress self-pulsating behaviour, $\lambda_{\mathrm{S}}$ should be better isolated from the $\lambda_{\mathrm{L}}$ gain medium. The power levels achieved are high enough to enable efficient intra-cavity frequency mixing.

\section{Conclusions}

We have designed and fabricated two different verticalcavity surface-emitting laser (VECSEL) gain mirrors that are capable of providing gain simultaneously at two well-separated wavelengths. The first design, $S 1$, had one gain region and the second design, $S 2$, had two gain regions, one for each wavelength, separated by an optical long-wave pass filter. The VECSEL using the $S 1$ gain mirror design generated a maximum optical power of $0.39 \mathrm{~W}$ (140 $\mathrm{mW}$ in continuous wave mode) at $982 \mathrm{~nm}$ and $0.3 \mathrm{~W}(115 \mathrm{~mW})$ at $1042 \mathrm{~nm}$, whereas the VECSEL using the $S 2$ gain mirror design generated $0.75 \mathrm{~W}(300 \mathrm{~mW})$ at $966 \mathrm{~nm}$ and $1.38 \mathrm{~W}(300 \mathrm{~mW})$ at $1047 \mathrm{~nm}$. Both lasers exhibited self-pulsation at high output powers. $S 1$ sets higher requirements on growth precision, but the VECSEL using this gain mirror design exhibited better equalized output power between the wavelengths. In addition to higher output power, the VECSEL using the $S 2$ gain mirror design exhibited a larger separation between the operation wavelengths. Based on our experiments, we believe dual-wavelength VECSELs are a suitable route for demonstrating a compact solution for dual-wavelength emission and intracavity difference frequency generation.

\section{Acknowledgement}

This research has been supported by the Academy of Finland through the projects \#115810 and \#109080.

\section{References}

[1] W. Chen, J. Cousin, E. Poullet, J. Burie, D. Boucher, X. Gao, M.W. Sigrist, and F.K. Tittel, Continuouswave mid-infrared laser sources based on difference frequency generation, Comptes Rendus Physique 8(10), 1129-1150 (2007).

[2] C. Wang, Y. Chuang, and C. Pan, Two-wavelength interferometer based on a two-color laser-diode array and the second-order correlation technique, Opt. Lett. 20(9), 1071-1073 (1995).

[3] P. Pellandini, R.P. Stanley, R. Houdre, U. Oesterle, M. Ilegems, and C. Weisbuch, Dual-wavelength laser emission from a coupled semiconductor microcavity, Appl. Phys. Lett. 71(7), 864-866 (1997).

[4] C.-F. Lin, M.-J. Chen, and B.-L. Lee, Wide-range tunable dual-wavelength semiconductor laser using asymmetric dual quantum wells, IEEE Photon. Technol. Lett. 10(9), 1208-1210 (1998).

[5] C.-C. Huang, C.-H. Cheng, Y.-S. Su, and C.-F. Lin, 174-nm mode spacing in dual-wavelength semiconductor laser using nonidentical InGaAsP quantum wells, IEEE Photon. Technol. Lett. 16(2), 371-373 (2004).

[6] N. Basov, O. Bogdankevich, and A. Grasyuk, 9B4semiconductor lasers with radiating mirrors, IEEE J. Quantum Electron. 2(9), 594-597 (1966).

[7] M. Kuznetsov, F. Hakimi, R. Sprague, and A. Mooradian, High-power $(>0.5-\mathrm{W} \quad \mathrm{CW})$ diode-pumped vertical-external-cavity surface-emitting semiconductor lasers with circular TEM 00 beams, IEEE Photon. Technol. Lett. 9(8), 1063-1065 (1997).

[8] A. Tropper and S. Hoogland, Extended cavity surfaceemitting semiconductor lasers, Prog. Quantum Electron. 30(1), 1-43 (2006).

[9] S. Giet, A.J. Kemp, D. Burns, S. Calvez, M.D. Dawson, S. Suomalainen, A. Harkonen, M. Guina, O. Okhotnikov, and M. Pessa, Comparison of thermal management techniques for semiconductor disk lasers, in: Solid State Lasers XVII: Technology and Devices, eds. W.A. Clarkson, N. Hodgson, and R.K. Shori, Proc. SPIE 6871, 687115-10 (2008).

[10] W.J. Alford, T.D. Raymond, and A.A. Allerman, High power and good beam quality at $980 \mathrm{~nm}$ from a vertical 
external-cavity surface-emitting laser, J. Opt. Soc. Am. B 19(4), 663-666 (2002).

[11] J. Hopkins, A.J. Maclean, D. Burns, E. Riis, N. Schulz, M. Rattunde, C. Manz, K. Köhler, and J. Wagner, Tunable, single-frequency, diode-pumped 2.3- $\mu \mathrm{m}$ VECSEL, Opt. Express 15(13), 8212-8217 (2007).

[12] T. Leinonen, Y. Morozov, A. Harkonen, and M. Pessa, Vertical external-cavity surface-emitting laser for dualwavelength generation, IEEE Photon. Technol. Lett. 17(12), 2508-2510 (2005).

[13] Y. Morozov, T. Leinonen, A. Harkonen, and M. Pessa, Simultaneous dual-wavelength emission from vertical external-cavity surface-emitting laser: A numerical modeling, IEEE J. Quantum Electron. 42(9-10), 10551061 (2006).

[14] T. Leinonen, S. Ranta, A. Laakso, Y. Morozov, M. Saarinen, and M. Pessa, Dual-wavelength generation by vertical external cavity surface-emitting laser, Opt. Express 15(20), 13451-13456 (2007).

[15] Z.L. Liau, Semiconductor wafer bonding via liquid capillarity, Appl. Phys. Lett. 77(5), 651-653 (2000).

[16] S. Calvez, D. Bums, and M.D. Dawson, Optimization of an optically pumped 1.3- $\mu \mathrm{m}$ GaInNAs verticalcavity surface-emitting laser, IEEE Photon. Technol. Lett. 14(2), 131-133 (2002).

\title{
VIENALAIKIS DVIEJU BANGŲ GENERAVIMAS IŠ PUSLAIDININKINIU VERTIKALIAI SPINDULIUOJANČ́IO PAVIRŠIAUS LAZERIŲ SU IŠORINIU REZONATORIUMI
}

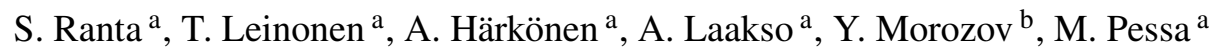 \\ ${ }^{a}$ Tamperès technologijos universiteto Optoelektronikos moksliniu tyrimu centras, Tamperè, Suomija \\ ${ }^{\mathrm{b}}$ Rusijos MA Radijo inžinerijos ir elektronikos instituto Saratovo skyrius, Saratovas, Rusija
}

\begin{abstract}
Santrauka
Pademonstruotas dviejų bangų generavimas iš optiškai kaupinamo vertikaliai spinduliuojančio paviršiaus lazerio su išoriniu rezonatoriumi (angl. tokio lazerio trumpinys yra VECSEL), naudojant dviejų skirtingų konstrukcijų stiprinančiuosius veidrodžius. Pirmoji stiprinančiojo veidrodžio konstrukcija $(S 1)$ leido generuoti $0,39 \mathrm{~W}$ galios $\lambda_{\mathrm{S}}=984 \mathrm{~nm}$ bangos ilgio spinduliuotę ir $0,30 \mathrm{~W}$ ga$\operatorname{lios} \lambda_{\mathrm{L}}=1042 \mathrm{~nm}$ spinduliuotę. VECSEL lazeris su antraja stiprinančiojo veidrodžio konstrukcija $(S 2)$ generavo maksimalią $0,75 \mathrm{~W}$
\end{abstract}

galios spinduliuotę, kurios bangos ilgis $\lambda_{\mathrm{S}}=966 \mathrm{~nm}$, ir $1,38 \mathrm{~W}$ galios spinduliuotę, kurios bangos ilgis $\lambda_{\mathrm{L}}=1047 \mathrm{~nm}$. VECSEL lazeriai su abiejų konstrukciju stiprinančiaisiais veidrodžiais išsiskyrè savipulsacija esant didelių išvadinių galių režimui. Lazeryje su $S 1$ konstrukcijos stiprinančiuoju veidrodžiu savipulsacijos prasidèdavo bangos $\lambda_{\mathrm{S}}$ galiai viršijus $140 \mathrm{~mW}$, o bangos $\lambda_{\mathrm{L}}-$ viršijus $115 \mathrm{~mW}$. Lazeryje su $S 2$ konstrukcijos stiprinančiuoju veidrodžiu savipulsacijos atsiradimo slenkstis esant atitinkamiems abiejų bangų ilgiams buvo $300 \mathrm{~mW}$. 